\title{
The influence of endodontic treatment on blood pressure reduction in patients with vital irreversible pulpitis
}

This article was published in the following Dove Press journal: Clinical, Cosmetic and Investigational Dentistry

\author{
Hashim M Hussein \\ Ahmed S Raafat \\ Zainab S Amory \\ Mohammed Jasim AL-Juboori \\ Department of Dentistry, Al-Rafidain \\ University-College, Baghdad, Iraq
}

Background: During endodontic treatment, endodontists must be aware of the various factors that may decrease or increase blood pressure. This study aimed to assess the mean percentages of systolic, diastolic, and arterial blood pressure (MSBP, MDAP, $\mathrm{MABP}$ ) reduction in patients with vital irreversible pulpitis in teeth and who were treated at three visits to endodontists in three age groups (20-34 years, 35-50 years, 51-65 years).

Materials and methods: A total of 100 teeth with vital irreversible pulpitis from 100 patients were included. All patients underwent 3 visits for endodontic treatment. The 1 st visit included removal of vital pulp tissue and a determination of working length, the 2 nd visit included canal preparation and widening, and at the 3rd visit the canal was obturated and sealed by gutta percha and sealer. Blood pressure for all patients was checked and documented once before starting treatment and three times during treatment at different intervals during all visits.

Results: There were significantly higher percentage reductions in MSBP, MDBP, and MABP at the 1st visit for endodontic treatment in comparison to other visits (2nd and 3rd) for all patients. Additionally, there were significantly higher percentage reductions in MSBP, MDBP, and MABP at the 1st visit for endodontic treatment in comparison to other visits in males and females, for all age groups, both anesthesia injection-type groups (infiltration and block), and all treated tooth types except mandibular anterior teeth, and there were nonsignificant differences among groups. However, there were nonsignificant differences in MSBP, MDBP, and MABP between males and females, between infiltration and block injection groups and in relation to teeth types at all visits.

Conclusions: The reduction of blood pressure in patients undergoing endodontic treatment of vital teeth with irreversible pulpits is common, especially at the 1 st visit for pulp extirpation.

Keywords: irreversible pulpitis, endodontic treatment, vital teeth, anesthesia, age, gender

\section{Introduction}

An increase in blood pressure (BP) is considered an important risk factor that may lead to death in patients around the world. ${ }^{1-3}$ A change in BP (increase or decrease) is related directly to the sensation of pain or anxiety in patients. This pain can serve as an alarm to the body to prevent damage to tissues, and the affected area can send signals to activate the sympathetic nervous system (SNS) through neurophysiological linkages. This can lead to increased heart rate and adrenal gland stimulation, which can result in an increase in BP. However, if the pain disappears, the same
Correspondence: Hashim M Hussein Department of Dentistry, Al-Rafidain University-College, Palestine Street, P.O. Box 46036, Baghdad, Iraq Tel +964780710 1071

Email hashimmueenhussein@gmail.com 
area sends another signal to activate the parasympathetic nervous system (PNS), which leads to decreased heart rate and hypotension. ${ }^{4-6}$

During dental treatment, especially endodontic treatment, the endodontist must know how to deal with healthy and compromised patients and how to complete root canal procedures successfully and without complications. ${ }^{3}$

Throughout the access-opening appointment, pain or anxiety may cause in activation of the SNS, leading to changes in heart rate and BP. This can be due to the release of endogenous catecholamines (adrenaline and noradrenaline) and not due to the effect of exogenous catecholamines found in local anesthetics. ${ }^{7,8}$ However, other authors have suggested that this change in BP or heart rate may be due to adrenaline present in local anesthetic solutions, which plays a role in prolonging the time that local anesthesia is effective and may cause unwanted side effects, such as increasing BP and heart rate as the vasoconstricting effect of adrenaline leads to increased contraction of blood vessels and increased blood flow. ${ }^{9,10}$ Pereira, in $2013,{ }^{11}$ discussed the effect of using local anesthesia with different concentrations of adrenaline at single-visit endodontic treatments of molars with pulpitis and found that adrenaline did not lead to significant alterations in heart rate or systolic and diastolic BP under clinical conditions. In 2008, Liau et al. ${ }^{12}$ explained the effect of both tooth extraction and local anesthesia (in different age groups) on the activation of internal catecholamines and changes in their concentrations in the body during extraction. Additionally, other studies have investigated the effect of performing restorations with and without local anesthesia. ${ }^{6}$

In this study, we recorded and analyzed BP measurements before and during root canal treatment at different time periods in the teeth of Iraqi patients with vital irreversible pulpitis treated over three visits. We assessed the mean percentage reductions of systolic blood pressure (SBP), diastolic blood pressure (DBP), and arterial blood pressure (ABP).

\section{Materials and methods}

In this study, we recruited 100 Iraqi patients (50 males, 50 females) from Baghdad with irreversible pulpitis in three age groups (group 1: 20-34 years, 31 patients; group 2: 35-50 years, 22 patients; group 3: 51-65 year, 47 patients). A written consent form was obtained from all patients for blood pressure measurements, root canal treatment agreement and publishing data. This study was approved by the Ethics Committee of Al-Rafidain University-College. All patients underwent complete root canal treatment (3 visits) under local anesthesia with $2 \%$ lidocaine with 1:100,000 epinephrine $(1.7 \mathrm{ml})$. The injection technique was either infiltration or inferior dental blocking according to the treated tooth.

The vitality of pulp was checked before giving anesthesia using a pulp tester and ethyl chloride spray; only vital teeth were selected for this study. Patients with systemic diseases, pregnancy, or mental retardation, those who where heavy smokers (more than $10 \mathrm{cig} / \mathrm{day}$ ), those who taking any medication for pain, and those with their 3rd molar teeth were excluded from the study. Anesthesia was given at each visit. All root canal treatments during each visit were performed with rubber dam isolation and by same endodontist. In the access-opening visit (1st visit), the vital pulp tissue was removed using a barbed broach, and the working length was determined by hand file (initial size) with the aid of an Apex locator (iPex IINSK, Japan) and digital X-ray sensor (RVG 6100 Carestream-Kodak, USA). Then, irrigation was performed with $2.5 \%$ sodium hypochlorite $(\mathrm{NaOCl})$ and finally with normal saline, after which the canals were dried with paper points. Finally, teeth were medicated with calcium hydroxide paste (Metapex-META BIOMED) applied in the root canals, and teeth were sealed with a temporary filling.

In the instrumentation or preparation visit (2nd visit), complete preparation of the root canal system was performed using Gold ProTaper rotary files from Dentsply with a Proglider. Repeated $2.5 \% \mathrm{NaOCl}$ irrigation was performed throughout the sequence of filing, and the final irrigation was with normal saline. Then, the canal was dried with a paper point and sealed with sterile cotton and a temporary filling.

In the obturation visit (3rd visit), the length of the canal was checked again using a digital X-ray sensor and irrigated with $2.5 \% \mathrm{NaOCl}$ and then with normal saline. The canal was then dried with a paper point, and the canals were obturated by gutta-percha cones (Dentsply) with a sealer (Apexit Plus-Ivoclar Vivadent) using a cold lateral condensation technique.

The technique used for accurately determining BP included seating the patient in a chair for approximately 5 mins before measurement, with the patient's feet on the floor in front of the chair and their hands on the chair arms. An upper-arm BP monitor (Beurer BM 58, Germany) was used in this study, and the cuff holder encircled at least $80 \%$ of the patient's upper arm. ${ }^{1,13,14}$ 
During each visit, both SBP and DBP were measured four times for each patient. The initial measurement (1st measurement) was taken before starting the treatment (before giving anesthesia). The minimum measurement (measured during treatment) represents the lowest value from three measurements taken during the treatment as follows: 1st measurement: measured 10 mins after starting treatment.

Second measurement: measured 20 mins after starting treatment.

Third measurement: measured 30 mins after starting treatment.

The mean arterial pressure was calculated using the following equation:

$$
\begin{aligned}
& 1 / 3(\text { systolicpressure }- \text { diastolicpressure }) \\
& \quad+\text { diastolicpressure }
\end{aligned}
$$

Mean SBP (MSBP), mean DBP (MDBP), and mean ABP (MABP) were calculated from the following equations:

MSBP reduction percentage $=($ initial $\mathrm{S}-$ minimal $\mathrm{S} /$

$$
\text { initial S) x 100\% }
$$

MDBP reduction percentage $=($ initial $\mathrm{D}-$ minimal $\mathrm{D} /$

$$
\text { initial D) } x 100 \%
$$

MABP reduction percentage $=($ initial $\mathrm{A}-$ minimal $\mathrm{A} /$

$$
\text { initial A) } \times 100 \%
$$

Patients with SBP higher than $140 \mathrm{mmHg}$ or DBP lower than $90 \mathrm{mmHg}$ (at rest) were excluded from the study.

Data were analyzed using SPSS software, and descriptive statistics, analysis of variance (ANOVA), least difference analysis (LSD) and Independent $t$-tests were used in our study. The results with $P$-values less than 0.01 are highly significant (HS), and the results with $P$ values between 0.01 and 0.04 are significant (S), while $P_{-}$ values equal to or greater than 0.05 represent nonsignificant (NS) results.

\section{Results}

This study included 100 patients, each with a tooth with irreversible pulpitis. Fifty teeth were selected from males, and fifty teeth were selected from females. The patients' ages ranged from 20 to 65 year: group 1 (20-34 years) included $31 \%$ of the patients, group 2 (35-50 years) included 22\%, and group 3 (51-65 years) included 47\%.

Maxillary and mandibular anterior teeth represented $6 \%$ of all the teeth. Maxillary premolars represented $19 \%$ of the teeth, mandibular premolars $14 \%$, maxillary molars $28 \%$, and mandibular molars $27 \%$. Fifty-two percent of teeth with pulpitis were treated under local infiltration anesthesia, while $48 \%$ were treated under inferior dental block anesthesia.

The MSBP percentage reductions were $8.45,5.38$, and 3.11 at the 1 st, $2 \mathrm{nd}$, and 3rd visits, respectively, the MDBP percentage reductions were $11.75,6.45$, and 3.27 at the 1st, 2nd, and 3rd visits, respectively, and the MABP percentage reductions were $10.21,6.10$, and 3.39 at the 1 st, 2nd, and 3rd visits, respectively. The percentage reductions in MSBP, MDBP, and MABP were significantly higher at the 1 st visit for root canal treatment than at both the 2nd and 3rd visits for all treated patients. Additionally, there were highly significant differences in MSBP, MDBP, and MABP between the 1st and 2nd visits,

\begin{tabular}{|c|c|c|c|c|c|c|c|c|}
\hline \multicolumn{5}{|c|}{ Descriptive } & \multicolumn{2}{|c|}{ ANOVA test } & \multicolumn{2}{|l|}{ LSD test } \\
\hline MBP & Visits & Teeth No. & Mean & SD & F-test & $P$-value & Visits & $P$-value \\
\hline \multirow[t]{3}{*}{ MSBP } & First visit & 100 & 8.45 & 5.40 & 47.61 & $0.000 / \mathrm{HS}$ & First visit $X$ second visit & $0.000 / \mathrm{HS}$ \\
\hline & Second visit & 100 & 5.38 & 3.22 & & & First visit $X$ third visit & $0.000 / \mathrm{HS}$ \\
\hline & Third visit & 100 & 3.11 & 2.36 & & & Second visit $X$ third visit & $0.000 / \mathrm{HS}$ \\
\hline \multirow[t]{3}{*}{ MDBP } & First visit & 100 & 11.75 & 8.75 & 56.75 & $0.000 / \mathrm{HS}$ & First visit $X$ second visit & $0.000 / \mathrm{HS}$ \\
\hline & Second visit & 100 & 6.45 & 3.95 & & & First visit $X$ third visit & $0.000 / \mathrm{HS}$ \\
\hline & Third visit & 100 & 3.27 & 2.17 & & & Second visit $X$ third visit & $0.000 / \mathrm{HS}$ \\
\hline \multirow[t]{3}{*}{ MABP } & First visit & 100 & 10.21 & 6.52 & 66.16 & $0.000 / \mathrm{HS}$ & First visit $X$ second visit & $0.000 / \mathrm{HS}$ \\
\hline & Second visit & 100 & 6.10 & 2.83 & & & First visit $X$ third visit & $0.000 / \mathrm{HS}$ \\
\hline & Third visit & 100 & 3.39 & 1.66 & & & Second visit $X$ third visit & $0.000 / \mathrm{HS}$ \\
\hline
\end{tabular}
1 st and 3 rd visits, and 2 nd and 3rd visits. Table 1

The participants were separated into 2 or more groups according to different clinical variables or factors (gender,

Table I Comparison of MSBP, MDBP, and MABP reduction percentages among patients receiving three endodontic treatment visits 
age, tooth type, anesthesia type). We found that the percentage reductions in MSBP, MSBP, and MABP at the 1st visit were significantly higher than those at the 2 nd and 3rd visits in males and females from all three age groups (group 1: 20-34, group 2: 35-50, group 3: 51-65), regardless of the anesthesia (infiltration or block) or tooth type except for mandibular anterior teeth, in which case mean reduction at the 1 st visit was higher than that at other visits but the difference was not significant. Tables $2-5$

Moreover, the percentage reductions in MSBP, MDBP, and MABP were higher in males than in females at all visits but were not significantly different. Additionally, there were highly significant differences in MSBP, MDBP, and MABP between the 1st and 2nd visits, 1st and 3rd visits, and 2 nd and 3rd visits, and there was a significant difference in MSBP between the 2nd and 3rd visits in males and in MDBP between the 2nd and 3rd visits in females. Table 2

Statistically, there were nonsignificant differences in the percentage reductions in MSBP, MDBP, and MABP among the three age groups at all visits except for MDBP at the 1st visit, where there was a significant difference. Additionally, there were highly significant differences in MSBP, MDBP, and MABP between the 1st and 2nd visits and the 1st and 3rd visits for group 1 . In group 2, there were highly significant differences in MDBP and MABP between the 1st and 2nd visits; however, for MSBP, there was a nonsignificant difference. There were significant differences in MDBP and MABP between the 2nd and 3rd visits, but for MSBP, the differences were highly significant. In group 3, there was a highly significant difference in MSBP between the 1 st and 2nd visits, 1 st and 3rd visits, and 2nd and 3rd visits, but not between the 2 nd and 3 rd visits. Table 3

There were nonsignificant differences in the percentage reductions in MSBP, MDBP, and MABP among the 6 teeth-type groups at all visits. Additionally, in the maxillary anterior teeth group, there were highly significant differences in MSBP, MDBP, and MABP between the 1st and 2nd visits and in MSBP and MABP between the 1st and 3rd visits in group 1; MDBP was not significantly different between the 1st and 3rd visits. Additionally, there were nonsignificant differences in MSBP and MDBP between the 2 nd and $3 r$ visits, whereas the difference in MABP was significant. In the group of mandibular anterior teeth, there were nonsignificant differences in MSBP, MDBP, MABP between the 1st and 2nd and 2nd and 3rd visits, but there were significant differences between MDBP and MABP at the 1st and 3rd visits. In the maxillary premolar group, there were highly significant differences between MDBP and MABP at the 1st and 2nd and the 1st and 3rd visits; for MSBP, the difference was highly significant between the 1st and 3rd visits and significant between the 1 st and 2 nd visits. In addition, there were nonsignificant differences in MDBP and MABP and a significant difference in MSBP between the 2nd and 3 rd visits. In mandibular premolars, there were highly significant differences in MSBP, MDBP, and MABP between the 1 st and 2nd, 1st and 3rd, and 2nd and 3rd visits except for the differences in MDBP and MABP between the 1st and 2nd visits, which were not significant. There were also nonsignificant differences in MSBP between the 2nd and 3rd visits. In the maxillary molar group, there were significant differences in MSBP and MDBP between the 1st and 2nd visits, but there was a highly significant difference in MABP. There was also a highly significant difference in MSBP, MDBP, and MABP between the 1 st and 3 rd visits. In contrast, there was a nonsignificant difference in MSBP between the 2nd and 3 rd visits but a highly significant difference in MDBP and a significant difference in MABP. In the mandibular molar group, there were highly significant differences in MSBP and MDBP between the 1st and 2nd, 1st and 3rd, and 2nd and 3rd visits, whereas for MABP, the difference was highly significant between the 1 st and 2 nd and the 1 st and 3 rd visits but not the 2 nd and 3 rd visits. Table 4

Finally, the percentage reductions in MSBP, MDBP, and MABP were higher in the infiltration group than in the blocking group at all visits, but this difference was not significant. Table 5

\section{Discussion}

We chose patients whose ages ranged from 20-65 years because these ages represent the ages at which most patients undergo root canal treatment for maintaining their teeth. The 51-65 age group constituted $47 \%$ of the total sample, and this may be related to the fact that younger patients may have less time to go to endodontists and maintain their teeth; additionally, financial factors may form a barrier that prevents them from making endodontic visits, or it may be related to dental or endodontic anxiety. ${ }^{15-18}$

This study showed a decrease in BP during treatment (minimum measured BP) at all visits. This is due to the fact that after anesthetizing the tooth with pulpitis, the pain decreases and disappears gradually, and the brain sends signals to activate the PNS, which leads to a decrease in $\mathrm{BP}$ in patients. ${ }^{5,6}$ 


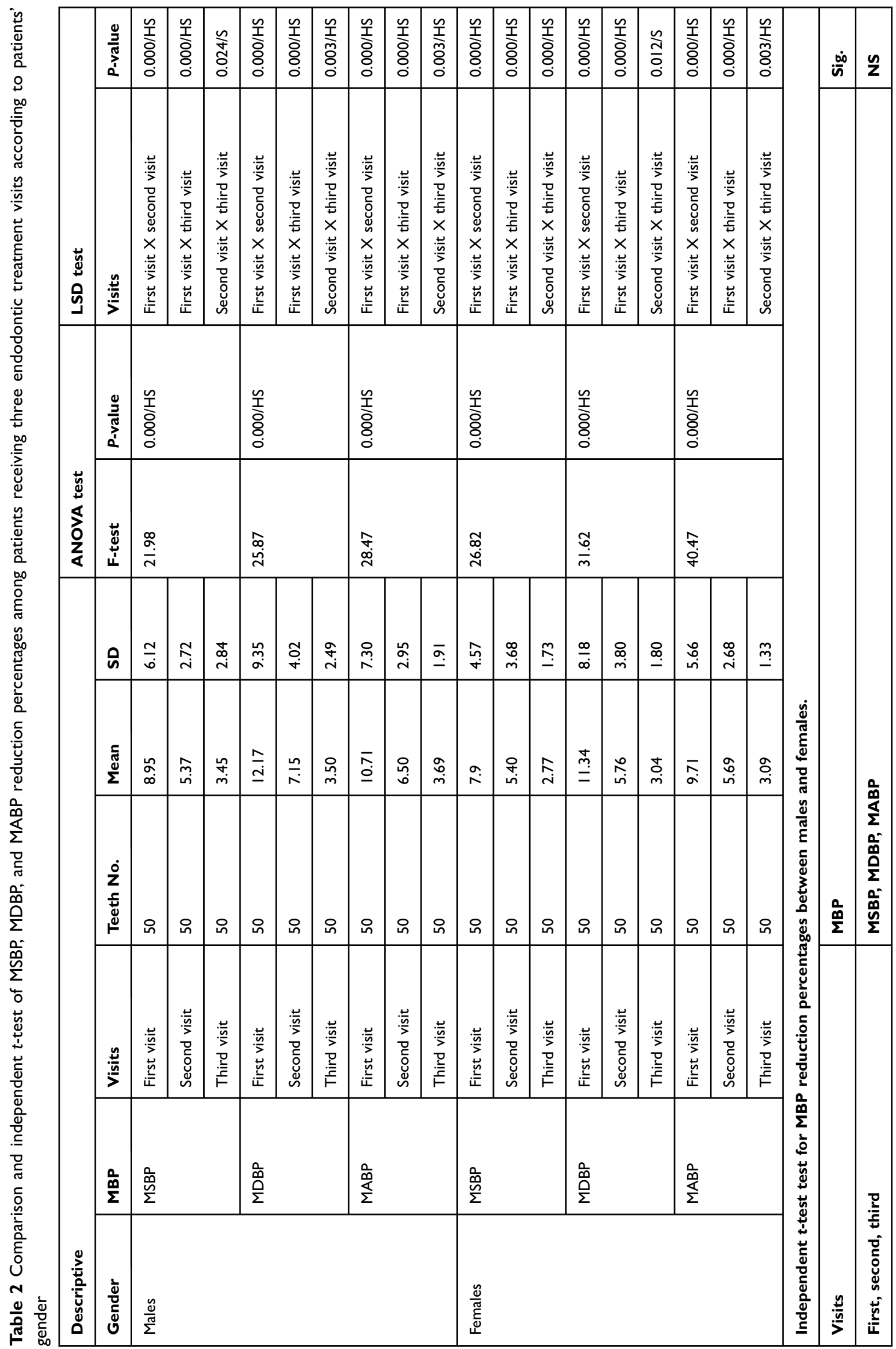




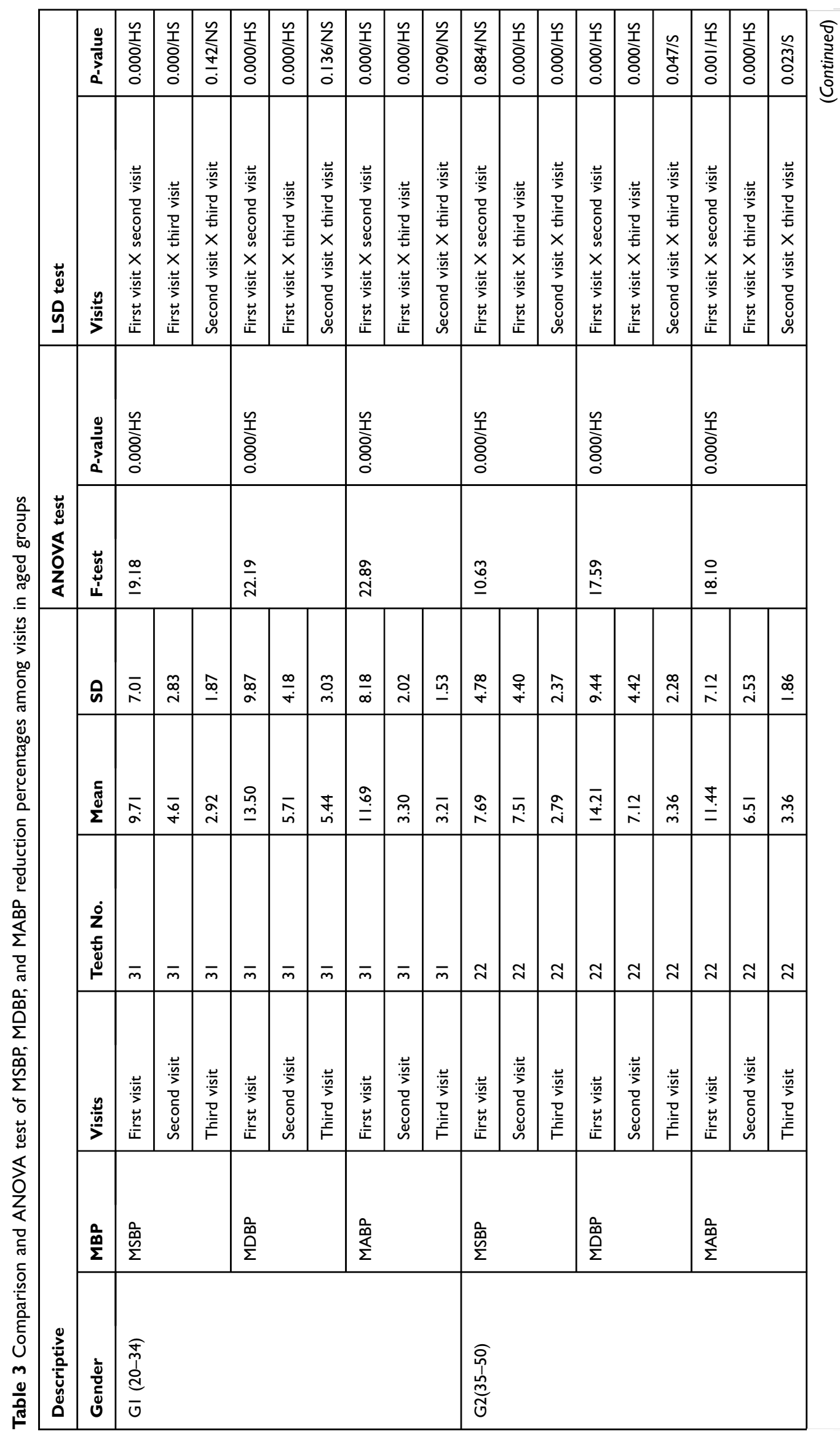




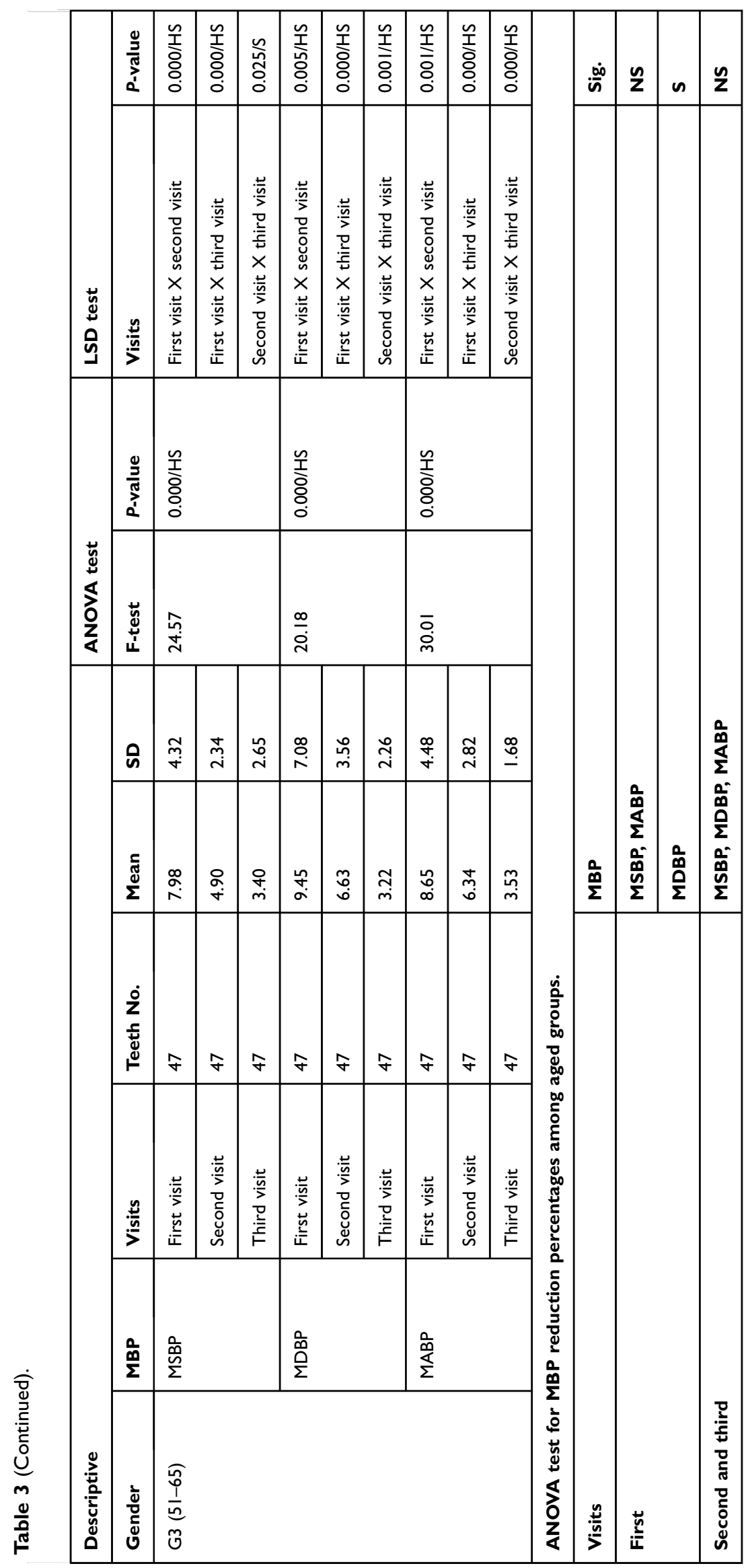




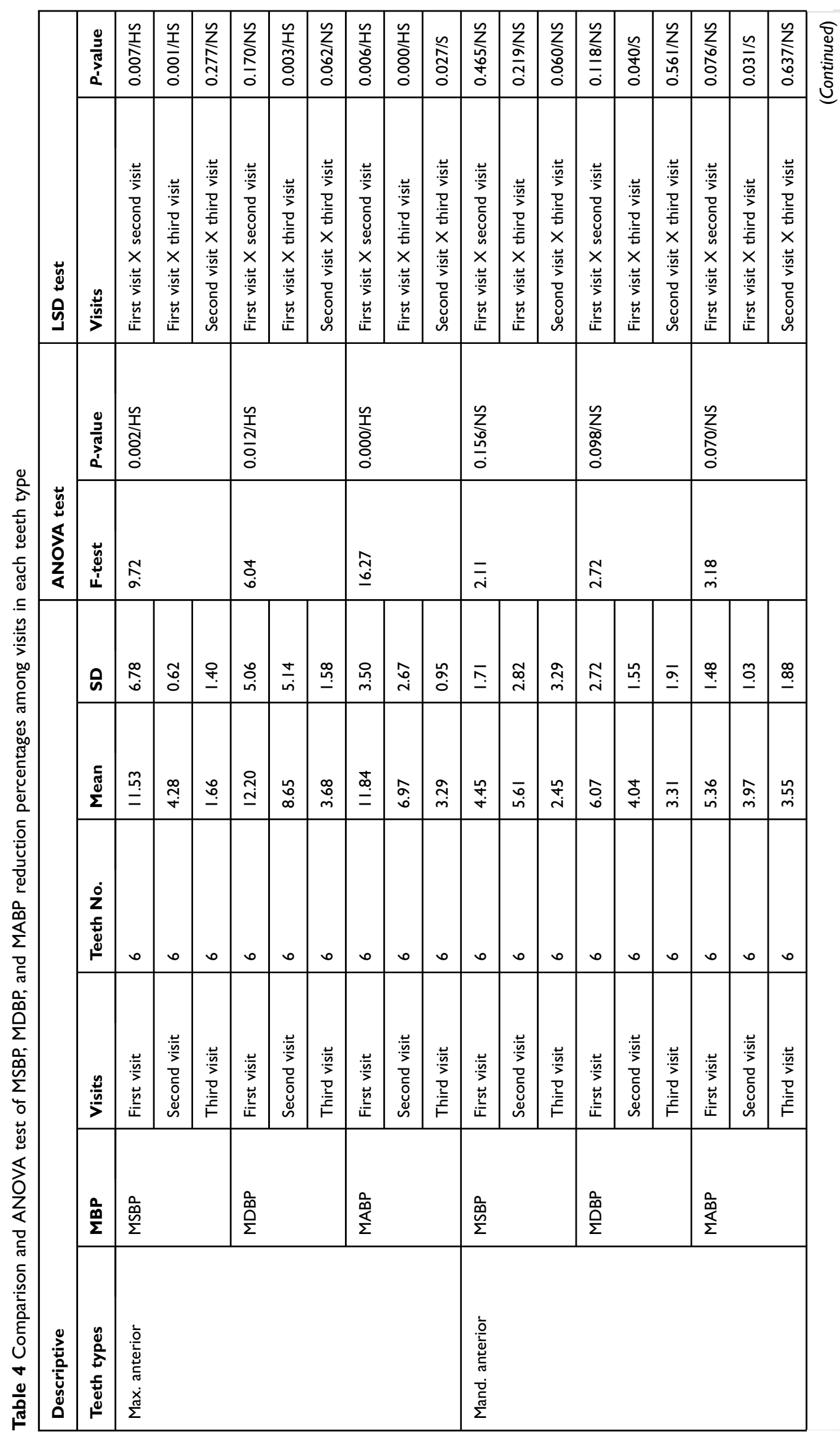




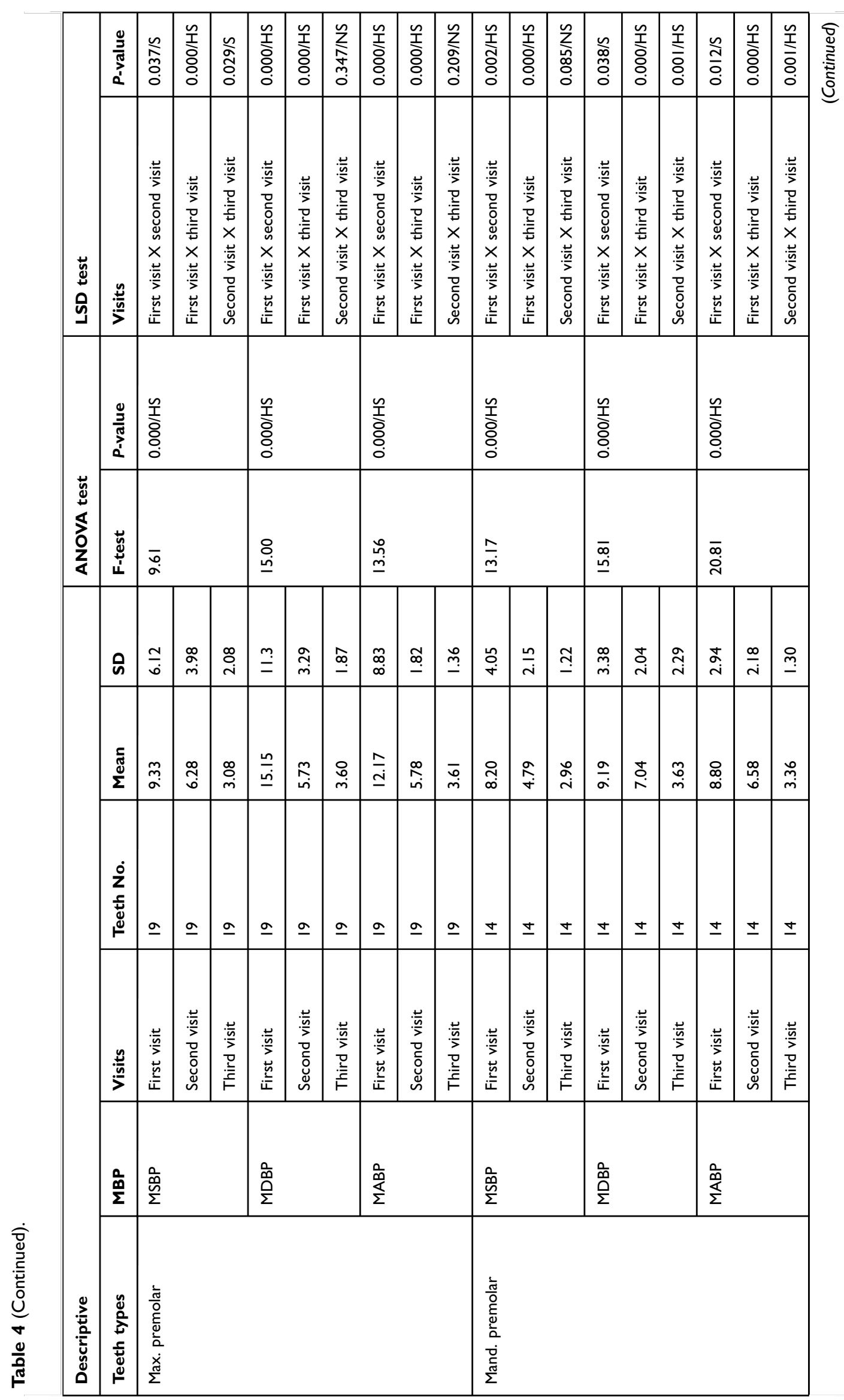




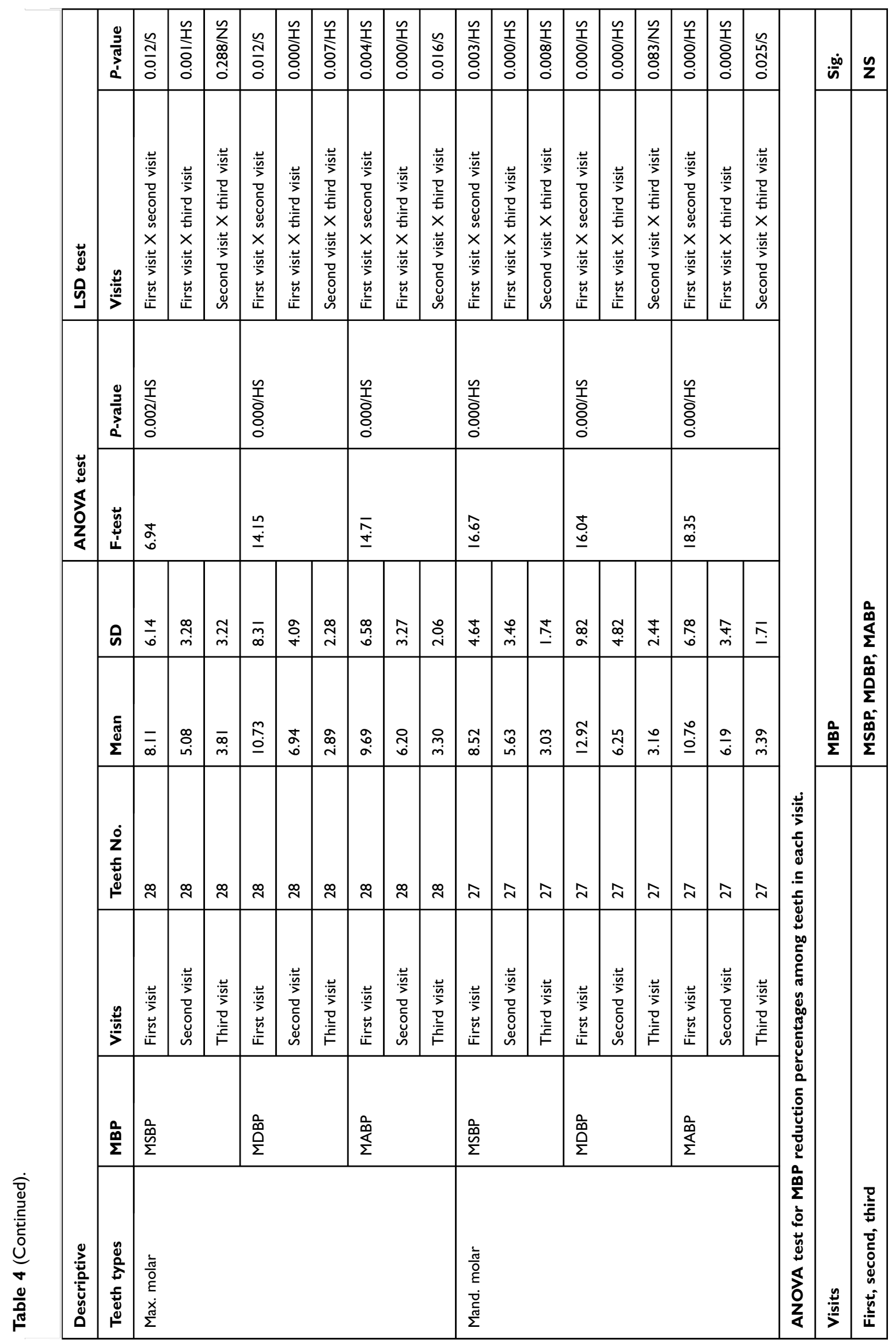




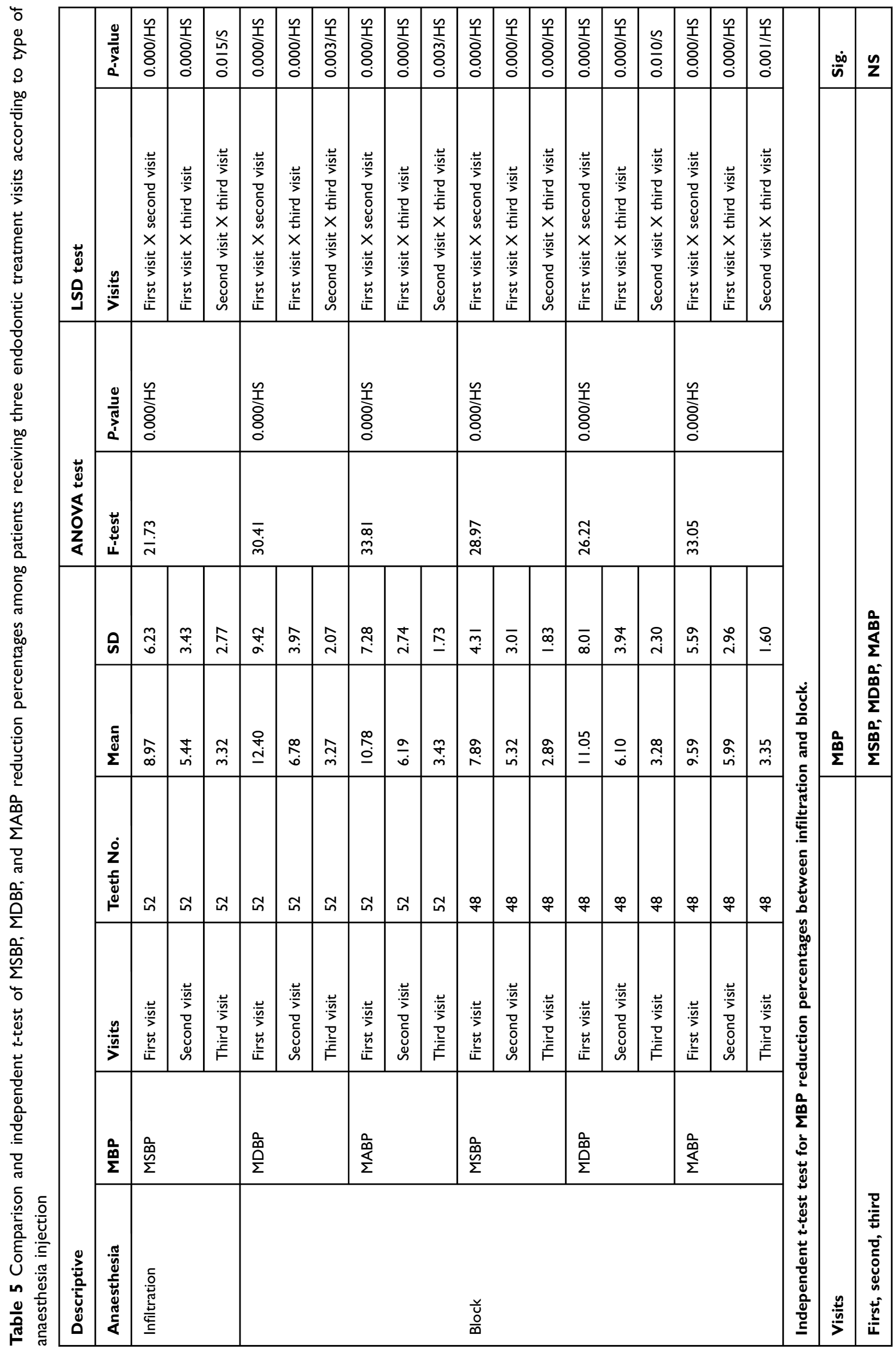


According to our study, the percentage reductions at the 1 st visit were significantly higher than at the 2nd and 3rd visits for all groups of clinical variables (gender, age, tooth type, anesthesia type), except in the mandibular anterior group, where there were nonsignificant differences. This may be related to the fact that in access opening (1st visit), the vital pulp tissue and nerve were extirpated and removed, while at the 2nd visit, there was minimal remaining pulp tissue, so intervention with the dental nerve branches was reduced or nonexistent; at the $3 \mathrm{rd}$ visit, there was no remaining pulp tissue. In the lower anterior dentition, which are enervated by incisive nerves, there are few terminal divisions of the inferior alveolar nerves. ${ }^{19}$ The dental nerves of the lower anterior dentition are a long way from the trigeminal ganglion and brainstem and may contain the least sensory fibers when compared with the dental nerves of the other tooth types. ${ }^{20}$ Along these lines, with complete removal of vital pulp tissue in these teeth, the reduced degree of trigeminal induction may prompt a small PNS impact on lowering BP. In total, these results agreed with Huang et al in 2017, ${ }^{6}$ except in specific age groups where Huang et al showed nonsignificant results only for patients below 40 years of age. This may be related to differences in age group selection as Huang et al divided their sample into 6 groups (20-29, 30-39, 40-49, 50-59, and 60-69 years), while our study divided the sample into only 3 groups (20-34, 3550 , and 51-65 years).

The percentage reductions in BP were higher in males than in females at all visits but are not statistically significant, and this result agrees with Huang et al in $2017 .^{6}$ This may be linked to the fact that females had greater average levels of anxiety than males. ${ }^{17,18}$ Therefore, the decreasing anxiety in males leads to activation of the PNS, which leads to a decrease in BP in males that is higher than that in females.

At the 1st visit, the percentage reductions in BP were higher in the 20-34 age group than in the other groups, while the 35-50 age group showed a higher reduction at the 2 nd visit. At the 3rd visit, the 51-65 age group showed a higher reduction than the other groups. These findings might be credited to the way that younger adults are most likely to be more restless or stressed while getting endodontic treatment than are older patients, and consequently, a significant SNS reaction is evoked that lessens or masks the PNS impact on BP in patients undergoing root canal treatment. Additionally, there was a nonsignificant difference in the percentage reductions in MSBP, MDBP, and
MABP among the three age groups at all visits except for MDBP at the 1st visit where there was a significant difference, which disagrees with Huang et al in $2017^{6}$ which showed nonsignificant results at all visits. This may be related to differences in age group selection.

Moreover, at the 1st visit, the percentage reductions in BP were higher in the maxillary anterior and premolar groups than in the other groups, while the least reduction was is the mandibular anterior group. This might be connected to the fact that the anterior and middle superior alveolar nerves supply the maxillary anterior and premolar teeth sequentially and represent the main branches of the infraorbital nerve, whereas the lower anterior teeth are provided by the incisive nerves, which are separate nerves and are the small terminal divisions of the inferior alveolar nerves. ${ }^{19}$ Additionally, there were nonsignificant differences in the percentage reductions in MSBP, MDBP, and MABP among the six teeth-type groups at all visits, and this agrees with Huang et al in $2017 .^{6}$

Finally, the percentage reductions in BP were higher in the infiltration group than in the blocking group at all visits, but the differences were not significant, and this result disagrees with Huang et al in 2017, ${ }^{6}$ which showed a higher percentage reduction in the block anesthesia group than in the infiltration group, with nonsignificant differences. Rogers et al in $2014^{21}$ and Shapiro et al in $2018^{22}$ were found that the success rate of anesthesia was increased with the using of both inferior dental blocking and supplemental buccal infiltration than inferior dental blocking only to anesthetized mandibular molars teeth with irreversible pulpitis during access opening visit. This may be related to the nature of the bone of the maxilla, which is cancellous and trabecular or spongy, while the mandibular bone is compact, ${ }^{23}$ so infiltration anesthesia is faster and more effective than blocking, and patients given blocking anesthesia are probably more anxious and fearful when undergoing root canal treatment than are patients receiving infiltration anesthesia, which positively influenced BP reduction in the infiltration group. ${ }^{24}$

\section{Conclusion}

The reduction of BP in patients undergoing endodontic treatment of vital teeth with irreversible pulpits is a generally basic event, especially at the access opening visit. Moreover, the reduction of BP in younger patients are higher than older patients in access opening visit. Also, the reduction of $\mathrm{BP}$ in males was higher than 
females and in the infiltration group was higher than block group.

\section{Disclosure}

The authors report no conflicts of interest in this work.

\section{References}

1. Hogan J, Radhakrishnan J. The assessment and importance of hypertension in the dental setting. Dent Clin North Am. 2012;56(4):731745. doi:10.1016/j.cden.2012.07.003

2. Mozaffarian D, Benjamin EJ, Go AS, et al. Heart disease and stroke statistics-2015 update: a report from the American Heart Association. Circulation. 2015;131(4):e29-e322. doi:10.1161/CIR.0000000000 000152

3. Bogari DF, Bakalka GT, Hazzazi LW, et al. The prevalence of hypertension in endodontic clinics: a pilot study. Dentistry. 2016;6(4):1-4.

4. Brand HS, Abraham-Inpijn L. Cardiovascular responses induced by dental treatment. Eur J Oral Sci. 1996;104(3):245-252.

5. Sacco` M, Meschi M, Regolisti G, et al. The relationship between blood pressure and pain. J Clin Hypertens (Greenwich). 2013;15 (8):600-605. doi:10.1111/jch.12145

6. Huang JI, Chang HH, Liao WC, Lin CP, Kao CT, Huang TH. Blood pressure reduction in patients with irreversible pulpitis teeth treated by non-surgical root canal treatment. J Dent Sci. 2017;12(4):382387. doi:10.1016/j.jds.2017.05.001

7. Hondrum SO. Hypertensive episode in the dental office. Gen Dent. 1985;33(2):134-139.

8. Takahashi Y, Nakano M, Sano K, Kanri T. The effects of epinephrine in local anesthetics on plasma catecholamine and hemodynamic responses. Odontology. 2005;93(1):72-79. doi:10.1007/s10266-005-0044-y

9. Yamatsuta Y, Kanri T. Influence of epinephrine on peripheral blood flow. J Jpn Dent Soc Anesthesiol. 1986;17(1):479-489.

10. Nagoh T, Sano K, Kanri T. A study of localization to local anesthetics. Influence of concentration to epinephrine. JSPA. 1998;11(1):3-8.

11. Pereira LA, Groppo FC, Bergamaschi Cde C, et al. Articaine (4\%) with epinephrine $(1: 100,000$ or $1: 200,000)$ in intraosseous injections in symptomatic irreversible pulpitis of mandibular molars: anesthetic efficacy and cardiovascular effects. Oral Surg Oral Med Oral Pathol Oral Radiol. 2013;116(2):e85-e91. doi:10.1016/j.oooo.2011.10.045

12. Liau FL, Kok SH, Lee JJ, et al. Cardiovascular influence of dental anxiety during local anesthesia for tooth extraction. Oral Surg Oral Med Oral Pathol Oral Radiol Endod. 2008;105(1):16-26. doi:10.1016/j.tripleo.2007.03.015
13. Popescu SM, Scrieciu M, Mercut V, Tuculina M, Dascalu I. Hypertensive patients and their management in dentistry. Int Sch Res Notices. 2013;2013(410740):1-8.

14. Southerland JH, Gill DG, Gangula PR, Halpern LR, Cardona CY, Mouton CP. Dental management in patients with hypertension: challenges and solutions. Clin Cosmet Investig Dent. 2016;17(8):111120. doi:10.2147/CCIDE.S99446

15. Wall T, Nasseh K, Vujicic M. Most important barriers to dental care are financial, not supply related. Health policy institute-research brief. Am Dent Assoc. 2014;1-9.

16. Yarbrough C, Nasseh K, Vujicic M. Why adults forgo dental care: evidence from a New National Survey. Health policy instituteresearch brief. Am Dent Assoc. 2014;1-10.

17. Hussein HM, Saeed NA, Al-Zaka IM. Pathways of endodontic fear in different age groups for Iraqi endodontic patients. IDJ. 2017;39 (1):27-33.

18. Saeed NA, Hussein HM, Mahmood AA. Prevalence of dental anxiety in relation to sociodemographic factors using two psychometric scales in Baghdad. MDJ. 2017;14(1):38-50. doi:10.32828/mdj. v14i1.753

19. Baart JA, Brand HS. Local Anaesthesia in Dentistry. 2nd ed. Chapter 2: Anatomy of the Trigeminal Nerve. Cham, Switzerland: Springer; 2017.

20. Lipari A, Lipari L, Carini F, Gerbino A, Farina E. Somatotopy of the trigeminal complex: nerve, ganglion, nucleus. Euro Mediterr Biomed J. 2017;12(37):170-177.

21. Rogers BS, Botero TM, McDonald NJ, Gardner RJ, Peters MC. Efficacy of articaine versus lidocaine as a supplemental buccal infiltration in mandibular molars with irreversible pulpitis: a prospective, randomized, double-blind study. $J$ Endod. 2014;40(6):753-758. doi:10.1016/j.joen.2013.12.022

22. Shapiro MR, McDonald NJ, Gardner RJ, Peters MC, Botero TM. Efficacy of articaine versus lidocaine in supplemental infiltration for mandibular first versus second molars with irreversible pulpitis: a prospective, randomized, double-blind clinical trial. J Endod. 2018;44(4):523-528. doi:10.1016/j.joen.2017.10.003

23. Young B, Woodford P, O'Dowd G. Wheater's Functional Histology: A Text and Colour Atlas. 6th ed. Part 3: Organ system, Chapter 10: Skeletal tissues. Philadelphia: Elsevier; 2014.

24. Dantas MVM, Nesso B, Mituuti DS, Gabrielli MAC. Assessment of patient's anxiety and expectation associated with hemodynamic changes during surgical procedure under local anesthesia. Rev Odontol UNESP. 2017;46(5):299-306. doi:10.1590/18072577.02917
Clinical, Cosmetic and Investigational Dentistry

\section{Publish your work in this journal}

Clinical, Cosmetic and Investigational Dentistry is an international, peer-reviewed, open access, online journal focusing on the latest clinical and experimental research in dentistry with specific emphasis on cosmetic interventions. Innovative developments in dental materials, techniques and devices that improve outcomes and patient satisfaction and preference will be highlighted. The manuscript management system is completely online and includes a very quick and fair peer-review system, which is all easy to use. Visit $\mathrm{http}: / / \mathrm{www}$.dovepress.com/testimonials.php to read real quotes from published authors. 